\title{
Clinical efficacy of intranasal drug delivery by nebulization in chronic rhinosinusitis: a systematic review*
}

\author{
Gregory Reychler ${ }^{1,2,3,4}$, Claire Domachowski ${ }^{3}$, Anne-Claire Latiers ${ }^{4,5}$, François \\ Jamar ${ }^{5}$, Philippe Rombaux ${ }^{6}$ \\ 'Institut de Recherche Expérimentale et Clinique (IREC), Pôle de Pneumologie, ORL \& Dermatologie, Université Catholique de \\ Louvain, Brussels, Belgium \\ 2 Service de Pneumologie, Cliniques universitaires Saint-Luc, Brussels, Belgium \\ ${ }^{3}$ Haute Ecole Leonard de Vinci - Institut d'Enseignement Supérieur Parnasse-Deux Alice, Brussels, Belgium \\ ${ }^{4}$ Service de Médecine Physique et Réadaptation, Cliniques universitaires Saint-Luc, Brussels, Belgium \\ Service de Médecine Nucléaire, Cliniques universitaires Saint-Luc, Brussels, Belgium \\ Service d'Oto-rhino-laryngologie, Cliniques universitaires Saint-Luc, Brussels, Belgium
}

Rhinology 57: 2, 82 - 93, 2019

https://doi.org/10.4193/Rhin18.010

*Received for publication:

January 15, 2018

Accepted: September 13, 2018

\begin{abstract}
Background: Chronic rhinosinusitis (CRS) treatments aim to alleviate underlying inflammation or infection. Optimal modality of administration remains controversial, however inhalation is usually preferred. This systematic review summarizes the efficacy of delivery by nebulization of intranasal corticoisteroids or antibiotics on symptoms, histology, endoscopy scores, nasal obstruction, clinical outcomes and quality of life in CRS.
\end{abstract}

Method: Following the PRISMA guidelines, randomized controlled, comparative and cohort studies evaluating effects of treatment by nebulization in sinusitis were identified and reviewed from two databases (PubMed and Scopus). Two reviewers independently assessed study quality and reviewed the selected studies.

Results: 600 references were retrieved and 12 studies evaluating 377 patients were included. Different devices were used. Efficacy of nasal delivery by nebulization was systematically observed on symptoms and size of polyps and on inflammatory parameters in all studies. The presence of polyps improved the efficacy of the nebulization. The effectiveness of this form of antibiotics delivery was not convincing. Few side effects were noted and these only applied to nebulized antibiotics.

Conclusions: This systematic review shows that based on the present literature, nebulization is not better than nasal spray for the delivery of corticosteroids due to the positive results on symptoms, endoscopic appearance and histological outcomes. For antibiotics delivery, nebulization is not of added value.

Key words: sinusitis, sinus, nebulization

\section{Introduction}

Rhinosinusitis is one of the most common reasons for visiting a general practitioner ${ }^{(1)}$. Chronic rhinosinusitis (CRS), which is defined by at least 12 weeks of persistent symptoms despite maximal therapy ${ }^{(2)}$, affects $14 \%$ of the population at least once in their life and is associated with reduced quality of life $\mathrm{e}^{(3)}$.

Treatment of CRS is mainly symptomatic. Medical treatment ${ }^{(4)}$ is usually proposed as a first line and aims to treat the underlying inflammation ${ }^{(1)}$. Corticosteroids are the most prescribed drug for treating CRS with or without polyposis ${ }^{(5)}$ and these have a high level of evidence ${ }^{(2)}$. However, there is a low level of evidence for the efficacy of topical antibacterial therapy ${ }^{(2)}$.

Although the optimal modality of administration (oral, intranasal spray and nasal nebulization) remains controversial for corticosteroids ${ }^{(6)}$, they are usually delivered by the inhalation route which offers minimal systemic side-effects ${ }^{(7)}$. This route of administration is supported by level $1 \mathrm{~A}$ evidence ${ }^{(2)}$. Despite the fact there is no evidence to support one intranasal delivery 
modality over others ${ }^{(6)}$, nebulization is frequently proposed and some in vitro data suggests a possible better targeted deposition $^{(8)}$. The evidence for administering other drugs by nebulization $^{(9)}$, is anecdotal at best.

The aim of this systematic review was to summarize the efficacy of intranasal delivery of corticosteroids or antibiotics by nebulization on symptoms, histology, endoscopy scores, clinical outcomes and quality of life in CRS.

\section{Method}

\section{Protocol}

The Preferred Reporting Items for Systematic Reviews and Meta-Analyses (PRISMA) guidelines were consulted during the stages of design, analysis, and reporting ${ }^{(10)}$. According to these guidelines, the structured search, study selection, risk-of-bias assessment of individual studies and best-evidence-syntheses for relating risk-of bias to consistency of effect sizes are included in this review. The protocol for this review has been registered in the international prospective register of systematic reviews PROSPERO (Registration No. CRD42017068344).

\section{Eligibility criteria, sources and search strategy}

PubMed and Scopus online databases were screened for the primary search strategy from inception to May 2017. Two key terms were combined: « *sinus* » AND « nebuli* » for the patient and intervention category, respectively.

The full search strategy for PubMed was adapted for other databases using terms and Medical Subject Headings (MeSH) combined with Boolean operators. Manual searching of the reference lists from the identified articles, citation tracking of included articles, and use of the PubMed related articles option completed the database searches to avoid missing relevant studies.

\section{Study selection and exclusion criteria}

After removal of duplicates, abstracts were checked critically and independently for relevance by two independent investigators (C.D. and G.R.). Articles were included if they were research articles about studies evaluating the effects of corticosteroids or antibiotics by nebulization in sinusitis, written in English or French and not classified as case report, review or meta-analysis. Studies about children or animals were excluded (Table 1). The investigators reviewed full-text articles when inclusion or exclusion was unclear based on the title and abstract. Any disagreement about eligibility was resolved by consensus.

\section{Data extraction, study quality appraisal and risk of bias as- sessment}

Study details and data were extracted by two investigators (C.D. and G.R.). Collected data for each study included the design, sample characteristics (including number of participants, age
Table 1. Selection criteria.

\begin{tabular}{|c|c|c|}
\hline & Inclusion criteria & Exclusion criteria \\
\hline Patients & $\begin{array}{l}\text { - Human } \\
\text { - Adults } \\
\text { - Sinusitis }\end{array}$ & $\begin{array}{l}\text { - Animals } \\
\text { - Children } \\
\text { - Healthy subjects Nasal } \\
\text { cast } \\
\text { - Cystic fibrosis }\end{array}$ \\
\hline Interventions & $\begin{array}{l}\text { - In vivo studies } \\
\text { - Intranasal delivery of } \\
\text { corticosteroids or anti- } \\
\text { biotics by nebulization }\end{array}$ & - In vitro studies \\
\hline Comparator & $\begin{array}{l}\text { - Another method of } \\
\text { administration } \\
\text { - Placebo } \\
\text { - No treatment } \\
\text { - Intranasal delivery of } \\
\text { another drug by nebu- } \\
\text { lization }\end{array}$ & \\
\hline Outcomes & $\begin{array}{l}\text { - Quality of life } \\
\text { - All clinical symptoms } \\
\text { - Endoscopic evaluation } \\
\text { (Kupferberg grades, } \\
\text { Lund Mackay score...) } \\
\text { - Rhinometry } \\
\text { - Nasal pick inspiratory } \\
\text { flow } \\
\text { - Cytology of the nasal } \\
\text { cavity }\end{array}$ & - Deposition studies \\
\hline Design & $\begin{array}{l}\text { - Randomized control- } \\
\text { led trial } \\
\text { - Controlled study } \\
\text { - Cross-over study }\end{array}$ & $\begin{array}{l}\text { - Systematic review } \\
\text { - Meta-analysis } \\
\text { - Case report } \\
\text { - Descritpive study } \\
\text { - Cohort study } \\
\text { - Pilot study }\end{array}$ \\
\hline
\end{tabular}

group, disease and severity and inclusion/exclusion criteria of the study), devices and drugs nebulized, clinical outcomes and results, and side effects.

The same two investigators applied the quality index developed by Downs and Black for assessing quality of reporting (10 items), external validity ( 3 items), bias and confounding elements (13 items) and statistical power ( 1 item) of all the studies ${ }^{(11)}$. This quality index comprises 27 questions with a total maximum score of $28^{(12)}$. A grade ranging from "poor" (<14 points) to "excellent" (24-28 points) was assigned to each study evaluated based on this quality index ${ }^{(12)}$.

\section{Data synthesis}

The investigators considered the results of the studies. Descriptive results, mean comparison, side effects and adherence/completion rate were reported when available.

\section{Results}

\section{Study selection}

A total of 600 references were originally retrieved from the different databases (Figure 1). After removal of duplicates, 506 articles were identified and screened. At the end of the process, 


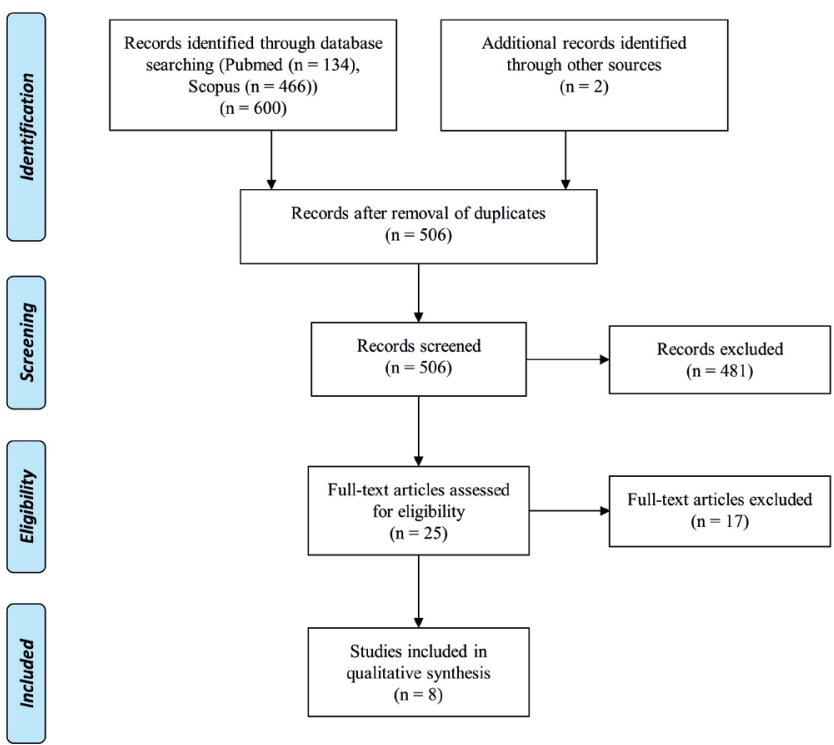

Figure 1. Flow diagram (Prisma Statement).

eight RCTs were included in the systematic review ${ }^{(13-20)}$.

\section{Characteristics of the studies}

The characteristics of the studies are described in Table 2 . The majority of the studies are recent $(6 / 8$ were published less than 5 years ago).

\section{Population and inclusion criteria}

A total of 263 patients were included from studies including 6 to 60 patients. Age ranged from 18 to 89 years. Five studies included patients with previous endoscopic surgery ${ }^{(13,15,16,18,19)}$. Naso-sinusal polyps were included in 4 studies $^{(13,17,20,21)}$ but only one study evaluated their sizes ${ }^{(20)}$.

\section{Interventions}

All the protocols used regarding method of delivery, drugs and devices (settings and properties) are summarized in Table 2. Nebulization was used alone or compared with oral treatment, nasal spray, nasal irrigation or nasal gel. Nebulized antibiotics have been studied as much as nebulized corticosteroids. Only one study combined both drugs ${ }^{(18)}$.

Different devices were found in the studies. Six studies used specific nebulizers to target the sinus(14,15,17,20,22) but only 4 performed the administration with sonic nebulizers ${ }^{(15,17,20,22)}$. Particle size was determined in 3 studies and the mass median aerodynamic diameter varied from 3.2 to $30 \mu \mathrm{m}^{(19,23)}$.

The durations of the treatment were heterogeneous, ranging from 7 days to 17 weeks. Regarding the nebulization, the duration of the session was highly variable but often not recorded.

\section{Outcomes}

Different outcomes were analyzed in the reviewed studies. Symptoms were evaluated in all studies. Six scales were used:
Visual Analogue Scale (VAS) ${ }^{(13,16,19)}$, Disease Specific Symptom Score (DSSS) ${ }^{(19)}$, Total Nasal Symptom Score ${ }^{(15,24)}$, Lund-Kennedy Score ${ }^{(18)}$ and Sino-Nasal Outcome Test (SNOT-20) ${ }^{(17)}$. The three last ones are specific to CRS. Olfaction evaluation by the Sniffin' Sticks Test (SST) and the Retro-Nasal Test (RNT) was presented as the outcome in one study ${ }^{(17)}$.

Nasal secretions were obtained in one study and cultured when any signs of purulence were present ${ }^{(22)}$. Endoscopic evaluations of polyps were performed by the Lund-Mackay score ${ }^{(15)}$, the Kupferberg grades ${ }^{(15)}$ and the Lund-Kennedy Endoscopic scale ${ }^{(18)}$. Acoustic rhinometry was used in one study to quantify the volume of nasal cavity and the resistance of upper airways ${ }^{(14)}$. Peak Nasal Inspiratory Flow (PNIF) was also used as a marker of efficacy in the same study ${ }^{(14)}$.

Quality of life was evaluated by one specific Rhinoconjunctivitis Quality of Life Questionnaire (RQLQ) or one generic questionnaire (Short-Form Health Survey 36 (SF-36)). VAS was used to quantify the symptoms from a predetermined list. The list of symptoms was variable even if nasal congestion/obstruction, pain and rhinorrhea were systematicaly evaluated.

\section{Quality and design of the studies}

The quality assessment of the reviewed studies is presented in Table 3. The scores obtained using the Downs and Black scale ranged from 14 to 23 and the median score was 19.5/28. All studies were classified as "Fair" or "Good" in the quality appraisal.

\section{Results of the studies}

All the results are reviewed in Table 4 and the main results are summarized by outcome herewith.

\section{Effects on symptoms}

Efficacy of nasal delivery by nebulization on symptoms was observed in nearly all studies using this method, independently of the nebulized drug.

Nebulized corticosteroids showed a bigger decrease in the total number of symptoms than nebulized saline solution, even if the difference in symptom number was not always significant ${ }^{(14,20)}$. The improvement was similar in nebulized corticosteroids and corticosteroids delivered by nasal spray ${ }^{(15)}$. In the three studies related to the nebulization of antibiotics ${ }^{(13,16,19)}$, symptoms were not improved by nebulization ${ }^{(13,16,19)}$. Both drugs were nebulized concomitantly in two studies from the same team. An improvement with nebulization was observed at short and long term follow-up and this was mainly related to the presence of polyps ${ }^{(18)}$. The effect disappeared 4 weeks after nasal spray delivery ${ }^{(18)}$.

\section{Effects on histology}

Corticosteroids reduced some inflammatory parameters but only when they were nebulized ${ }^{(20)}$. The combination of both ne- 
Table 2. Characteristics of the studies, populations, interventions and outcomes.

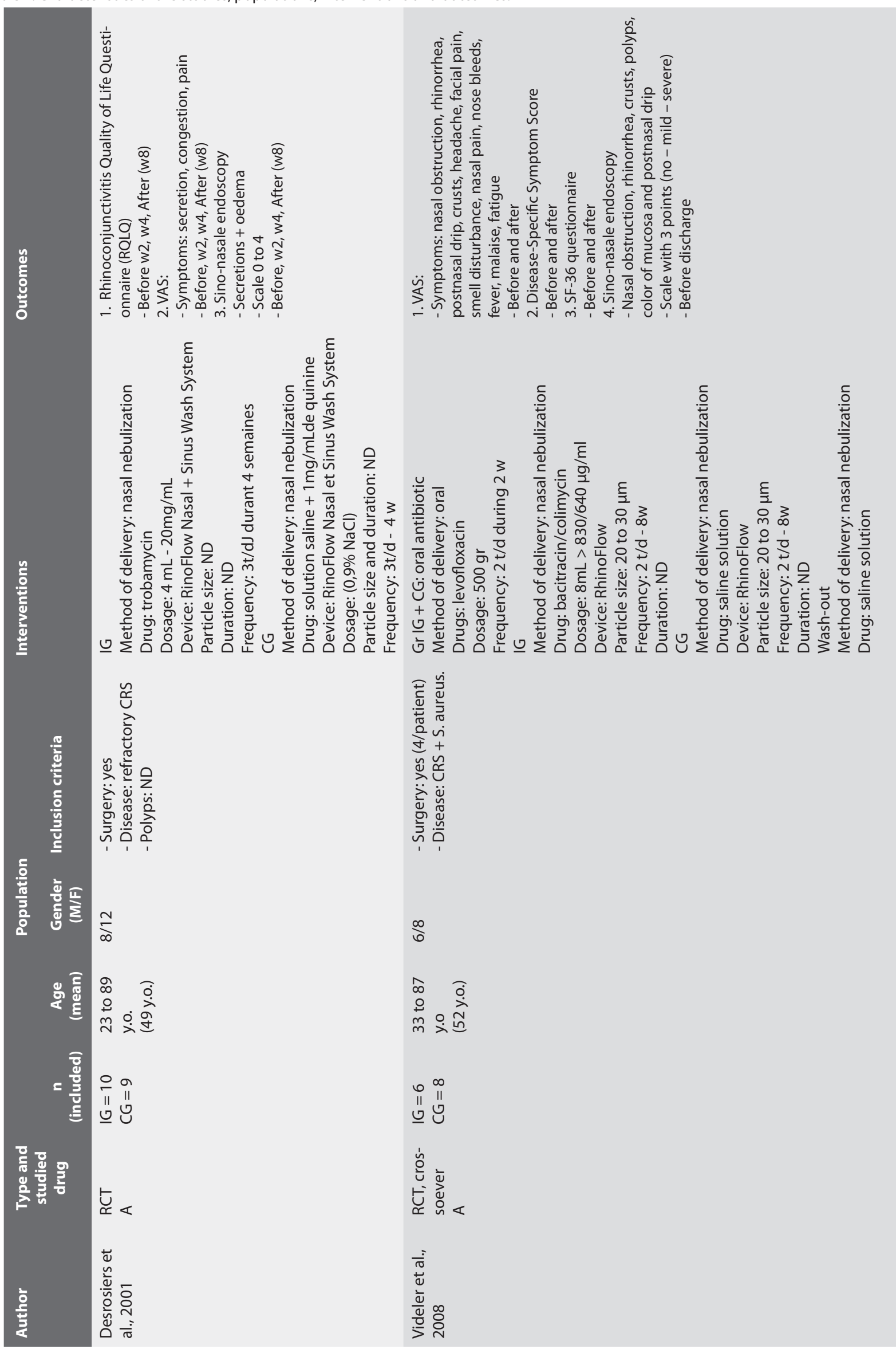


Table 2. Characteristics of the studies, populations, interventions and outcomes.

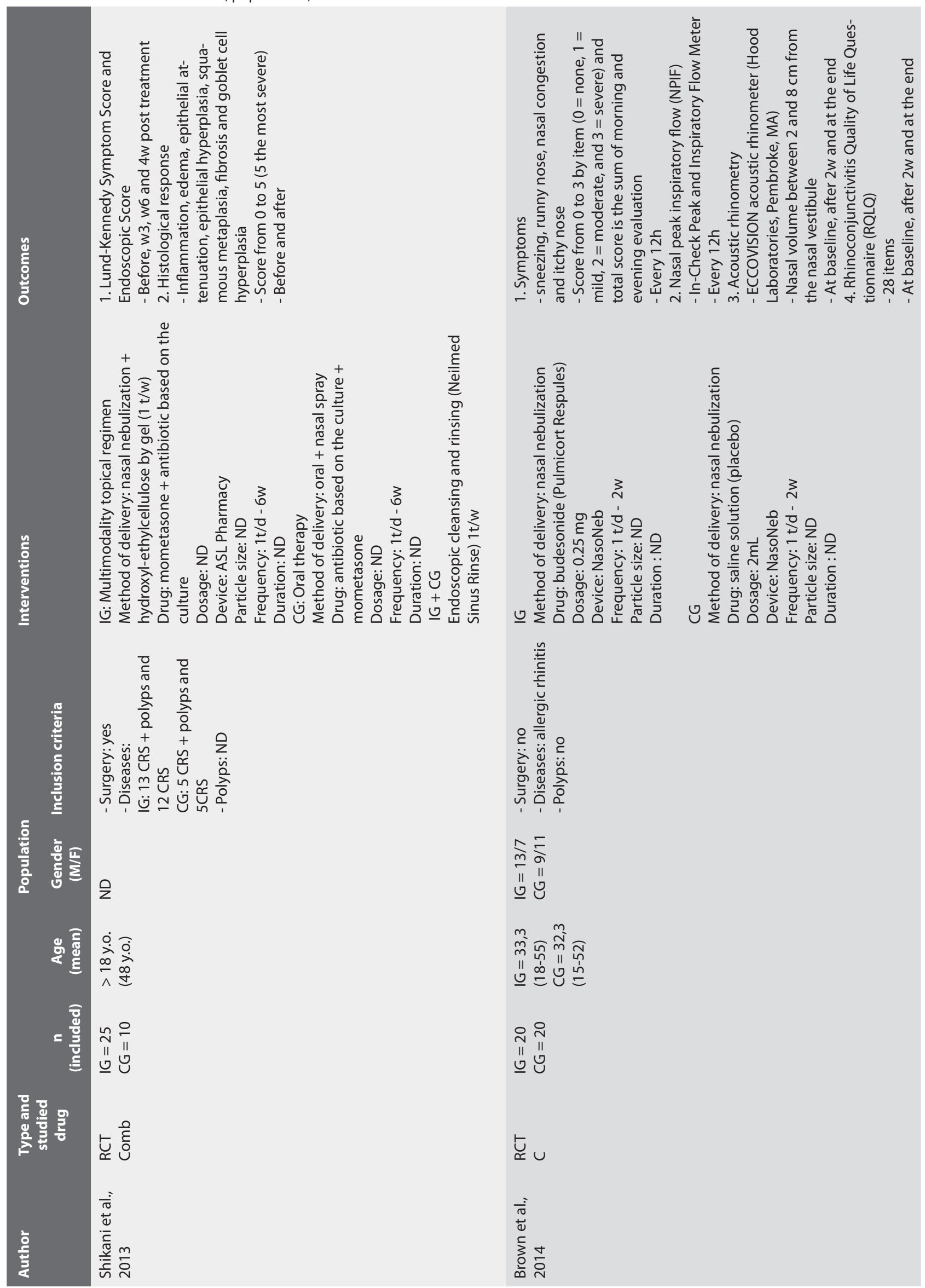


Table 2. Characteristics of the studies, populations, interventions and outcomes.

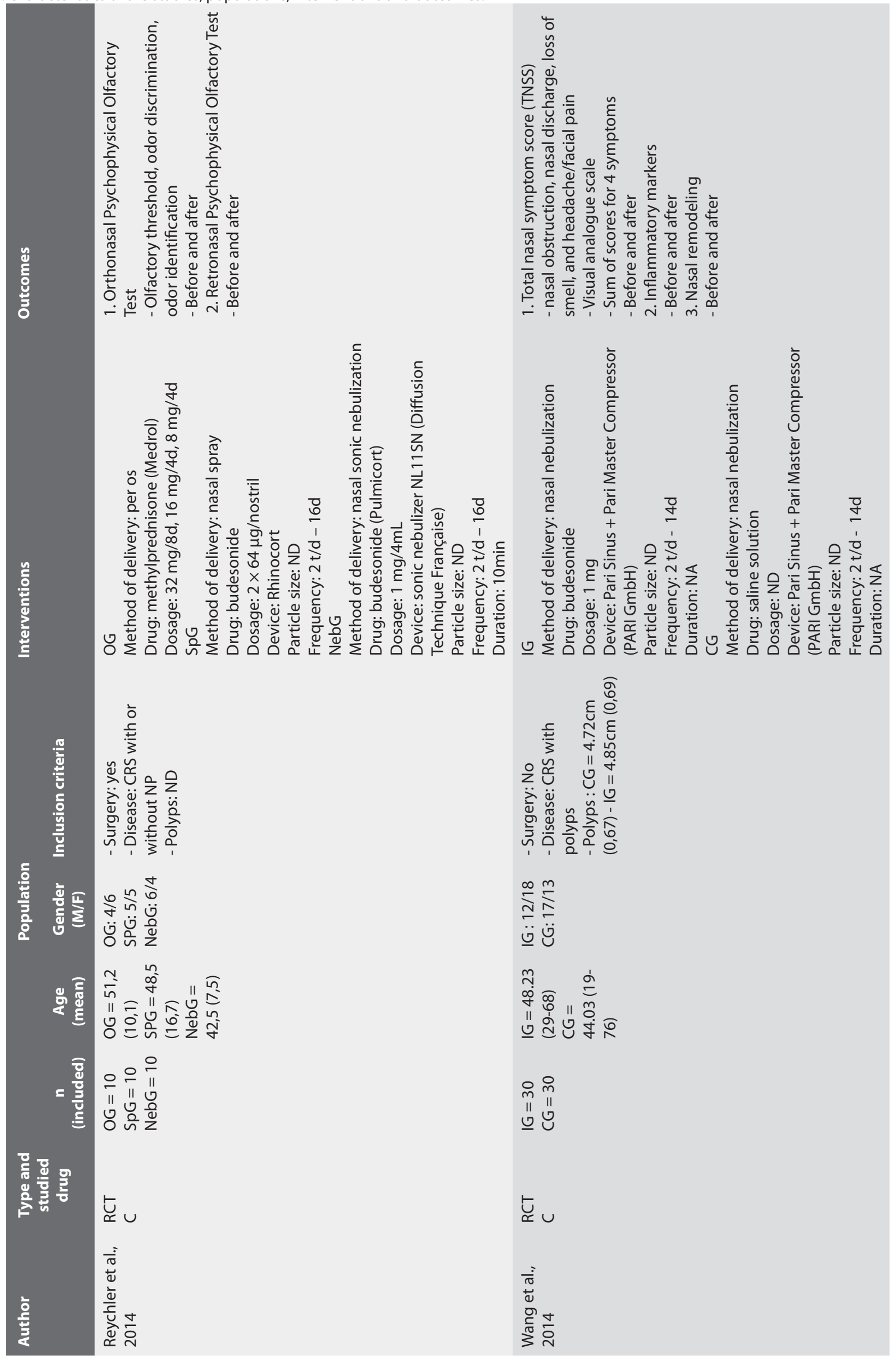


Table 2. Characteristics of the studies, populations, interventions and outcomes.

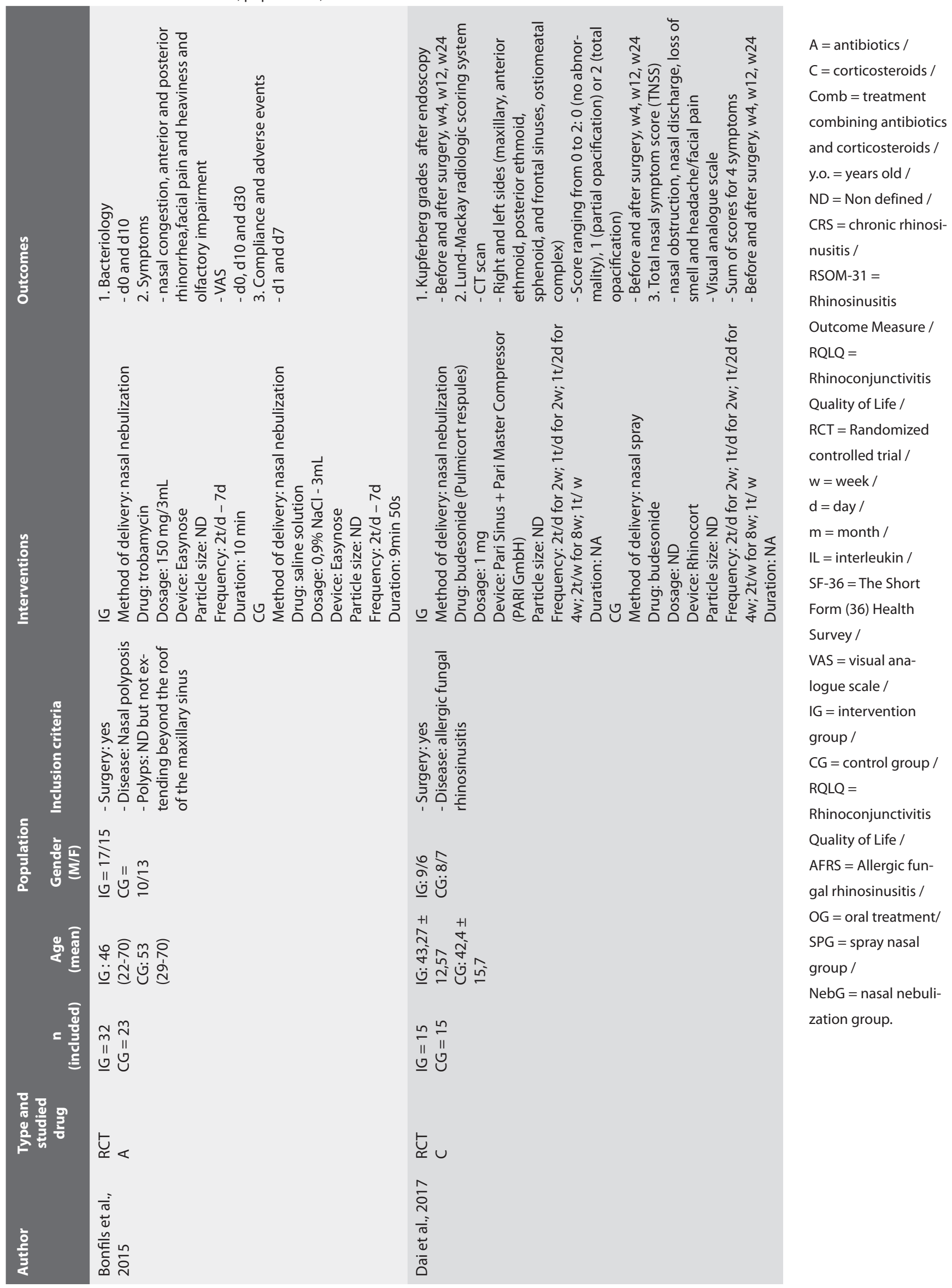


Table 3. Quality assessment of the selected studies using Downs and Black scale.

\begin{tabular}{|c|c|c|c|c|c|c|c|c|c|}
\hline & $\stackrel{\text { E }}{\underline{\Xi}}$ & 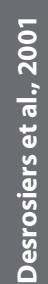 & 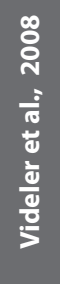 & 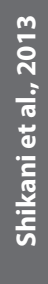 & 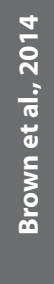 & 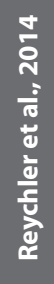 & 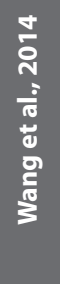 & 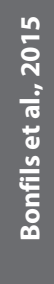 & 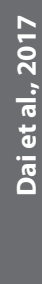 \\
\hline \multirow[t]{11}{*}{ Reporting } & 1 & 1 & 1 & 1 & 0 & 1 & 1 & 1 & 1 \\
\hline & 2 & 1 & 1 & 1 & 1 & 1 & 1 & 1 & 1 \\
\hline & 3 & 1 & 1 & 0 & 1 & 1 & 1 & 1 & 0 \\
\hline & 4 & 1 & 1 & 1 & 1 & 1 & 1 & 1 & 1 \\
\hline & 5 & 0 & 0 & 0 & 2 & 2 & 0 & 2 & 2 \\
\hline & 6 & 0 & 1 & 1 & 1 & 1 & 1 & 1 & 1 \\
\hline & 7 & 1 & 0 & 0 & 1 & 1 & 1 & 0 & 1 \\
\hline & 8 & 1 & 0 & 0 & 1 & 0 & 0 & 1 & 0 \\
\hline & 9 & 1 & 1 & 0 & 1 & 0 & 1 & 1 & 1 \\
\hline & 10 & 0 & 1 & 1 & 1 & 1 & 1 & 1 & 1 \\
\hline & Subtotal & 7 & 7 & 5 & 10 & 9 & 8 & 10 & 9 \\
\hline \multirow{4}{*}{$\begin{array}{l}\text { External } \\
\text { validity }\end{array}$} & 11 & 0 & 0 & 0 & 0 & 0 & 1 & 0 & 1 \\
\hline & 12 & 0 & 0 & 0 & 0 & 0 & 0 & 0 & 1 \\
\hline & 13 & 1 & 1 & 1 & 1 & 1 & 1 & 1 & 1 \\
\hline & Subtotal & 1 & 1 & 1 & 1 & 1 & 2 & 1 & 3 \\
\hline \multirow{14}{*}{$\begin{array}{l}\text { Internal } \\
\text { validity }\end{array}$} & 14 & 1 & 1 & 0 & 1 & 0 & 1 & 1 & 0 \\
\hline & 15 & 1 & 1 & 1 & 1 & 0 & 1 & 1 & 1 \\
\hline & 16 & 1 & 1 & 1 & 1 & 1 & 1 & 1 & 0 \\
\hline & 17 & 1 & 1 & 1 & 1 & 1 & 1 & 1 & 1 \\
\hline & 18 & 0 & 1 & 0 & 0 & 1 & 0 & 1 & 1 \\
\hline & 19 & 1 & 1 & 1 & 1 & 1 & 0 & 1 & 0 \\
\hline & 20 & 1 & 1 & 1 & 1 & 1 & 1 & 1 & 1 \\
\hline & 21 & 0 & 0 & 0 & 0 & 0 & 1 & 0 & 1 \\
\hline & 22 & 1 & 0 & 0 & 1 & 0 & 1 & 0 & 1 \\
\hline & 23 & 1 & 1 & 1 & 1 & 1 & 1 & 1 & 1 \\
\hline & 24 & 0 & 0 & 1 & 0 & 1 & 0 & 1 & 0 \\
\hline & 25 & 0 & 0 & 0 & 0 & 1 & 0 & 1 & 1 \\
\hline & 26 & 1 & 0 & 0 & 1 & 0 & 0 & 1 & 1 \\
\hline & Subtotal & 9 & 8 & 7 & 9 & 8 & 8 & 11 & 9 \\
\hline \multirow[t]{3}{*}{$\begin{array}{l}\text { Statistical } \\
\text { power }\end{array}$} & 27 & 1 & 0 & 1 & 1 & 1 & 1 & 1 & 1 \\
\hline & Total & 18 & 16 & 14 & 21 & 19 & 19 & 23 & 22 \\
\hline & $\begin{array}{l}\text { Quality } \\
\text { level }\end{array}$ & $\mathrm{F}$ & $\mathrm{F}$ & $\mathrm{F}$ & G & G & G & G & G \\
\hline
\end{tabular}

$\mathrm{F}$ : fair quality level; $\mathrm{G}$ : good quality level

bulized drugs in the same treatment sessions demonstrated an effect only in patients with polyps. This effect was not observed with the nasal spray ${ }^{(18)}$.

\section{Effects on endoscopic evaluation}

The size of polyps decreased with the delivery of corticosteroids by nebulization ${ }^{(15,20)}$. After treatment with budesonide, an intergroup difference was observed in favor of nebulization compared to administration by spray ${ }^{(15)}$ or placebo ${ }^{(20)}$.

After tobramycin administration the endoscopic results improved, but there was no difference between nebulization and nasal spray ${ }^{(16)}$. In another study the effect of nebulized aminoglycosides was not different from saline solution nebulization, but the patients received oral antibiotics in both groups ${ }^{(19)}$.

Patients without polyps did not demonstrate benefit from the treatment when corticosteroids and antibiotics were nebulized concomitantly ${ }^{(18)}$.

\section{Effects on nasal obstruction}

Only nebulized budesonide resulted in increased PNIF, even if the change magnitude was not different compared to saline nebulization ${ }^{(14)}$. However, in the same study, no difference in rhinometry improvement was observed between budesonide and saline nebulization ${ }^{(14)}$.

Saline nebulization performed better than tobramycin nebulization in nasal obstruction ${ }^{(16)}$.

\section{Effects on quality of life}

The quality of life of these patients was reduced compared to the general population ${ }^{(19)}$.

Quality of life was improved by nebulized corticosteroids but it was not different to saline solution nebulization ${ }^{(14)}$.

No benefit was observed on quality of life after tobramycin nebulization compared to nasal spray delivery or nebulized saline solution $^{(16,19)}$.

\section{Effects on bacteriology}

No study evaluated the effects of corticosteroids on bacteriology.

One study evaluated the effect of tobramycin on cultures ${ }^{(13)}$. Efficacy on the initial bacteria was verified with eradication of $47 \%$ of strains ${ }^{(13)}$.

\section{Side-effects}

Few side effects were noted in the retrieved studies ${ }^{(13,20)}$. The side-effects were always resolved by an adapted treatment.

\section{Discussion}

To our knowledge, this is the first systematic review to focus on the effects of nasal corticosteroids or antibiotics delivery by nebulization in CRS. The aim of the systematic review was to summarize the clinical efficacy and the impact on histological parameters, endoscopy scores, nasal obstruction and quality of life related to the nebulized method of delivery. The retrieved studies suggest that nasal nebulization of these drugs is an 
Authors

\section{Results}

Desrosiers et al., 2001 IG vs CG: pain(w2) and nasal congestion(w2, w4, w8) were higher, no difference for QoL or endoscopy IG + CG: QoL, symptoms and endoscopy improved at w2, w4 and w8

\begin{tabular}{|c|c|c|}
\hline & $\begin{array}{l}\text { difference for QoL or endoscopy IG + CG: QoL, symptoms and endoscopy } \\
\text { improved at w2, w4 and w8 }\end{array}$ & \\
\hline Videler et al., 2008 & $\begin{array}{l}\text { 1.VAS } \\
\text { Crusts and facial pain decreased significantly in IG and CG } \\
\text { No difference in symptom severity reduction between groups: nasal obstruc- } \\
\text { tion }(p=0.38) \text {, rhinorrhea }(p=0.84) \text {, postnasal drip }(p=0.22) \text {, crusts }(p=0.64) \text {, } \\
\text { headache }(p=0.90) \text {, facial pain }(p=0.53) \text {, smell disturbance }(p=0.72) \text {, na- } \\
\text { sal pain }(p=0.50) \text {, nose bleeds }(p=0.36) \text {, fever }(p=0.25) \text {, malaise }(p=0.07) \text {, } \\
\text { fatigue }(p=0.42) \\
\text { 2. Disease-Specific Symptom Score } \\
\text { Improvement after treatment in IG and in CG } \\
\text { No difference between groups } \\
\text { 3. SF-36 questionnaire } \\
\text { Before: lower than normal for all items } \\
\text { After: no improvement } \\
\text { 4. Endoscopy } \\
\text { No difference after treatment between modalities } \\
\text { Color of secretions improved in IG ( } p<0.0001)\end{array}$ & No side effect \\
\hline Shikani et al., 2013 & $\begin{array}{l}\text { 1. Lund-Kennedy Symptom Score } \\
\text { IG vs CG: NA in CRS without polyps but significant difference at w6 }(p<0.001) \\
\text { and w10 }(p=0.003) \text { in CRS with polyps } \\
\text { Improvement in IG at w3 and after for CRS without polyps }(p=0.003) \text { but no } \\
\text { difference after } 10 w \text { in CG } \\
\text { Improvement at w3 in both groups for CRS with polyps but no difference in } \\
\text { CG } \\
\text { 2. Endoscopic Score } \\
\text { Improvement in IG for CRS with and without polyps } \\
\text { 3. Histological response } \\
\text { Improvement only for CRS with polyps in IG }\end{array}$ & ND \\
\hline Brown et al., 2014 & $\begin{array}{l}\text { 1. Symptoms } \\
\text { IG vs CG: Bigger decrease in IG }(-3.3 \text { vs }-2.0) \text { than in CG but non significantly } \\
\text { Decrease after } 2 \text { and } 4 \text { days in IG and CG respectively } \\
\text { 2. Nasal peak inspiratory flow } \\
\text { No difference in change between groups }(+36 \mathrm{~L} / \mathrm{min} \text { vs }+18 \mathrm{~L} / \mathrm{min} ; \mathrm{p}=0.09) \\
\text { Increase only in IG ( } \mathrm{p}=0.03 \text { ) } \\
\text { 3. Acoustic rhinometry } \\
\text { No difference between groups at visit } 2 \text { and visit } 3 \\
\text { 4. Rhinoconjunctivitis Quality of Life Questionnaire }(\mathrm{RQLQ}) \\
\text { No difference between groups ( } w 2: \mathrm{p}=0.33 \text { and } w 4: p=0.41) \\
\text { Improvement for IG and CG at } \mathrm{w} 2 \text { and } w 4(p<0.001)\end{array}$ & ND \\
\hline Reychler et al., 2014 & $\begin{array}{l}\text { 1. Orthonasal Psychophysical Olfactory Test } \\
\text { Greater improvement for total score and odor discrimination in OG and NebG } \\
\text { vs SpG }(p<0.05) \\
\text { 2. Retronasal Psychophysical Olfactory Test } \\
\text { No difference between groups ( } p=0.231 \text { ) } \\
\text { 3. Adherence } \\
100 \% \text { for all groups }\end{array}$ & ND \\
\hline Wang et al., 2014 & $\begin{array}{l}\text { 1. Symptoms } \\
\text { IG vs CG: TNSS ( } p=0.001) \text {, polyps size }(p=0.01) \text {, nasal congestion }(p=0.001) \text {, } \\
\text { rhinorrhea }(p=0.001) \text {, loss of smell }(p=0.001) \text {, headache }(p=0.001) \\
\text { 2. Inflammatory markers } \\
\text { IG vs CG:? } \\
\text { IG: improvement of eotaxin, IL-5, IL-10 and TGFbeta }(p<0.05) \text { but no diffe- } \\
\text { rence for IL-17 and IFN-g; eosinophil numbers decreased; TH2, TH1, TH17, TR1 } \\
\text { and nTreg cells improved } \\
\text { CG: no alteration of the level of any cytokines, eosinophil numbers and cells } \\
\text { types } \\
\text { 3. Nasal remodeling } \\
\text { Affected in IG but not in CG } \\
\text { 4. Adherence } \\
\text { IG: } 2 \\
\text { CG: } 1\end{array}$ & $\begin{array}{l}\text { No side effect } \\
\text { Nasal dryness in } 5 \text { patients from IG }\end{array}$ \\
\hline
\end{tabular}

\section{Side-effects}

ND

1. Orthonasal Psychophysical Olfactory Test

vs SpG $(p<0.05)$

Retronasal Psychophysical Olfactory Test

$100 \%$ for all groups

IG vs CG: TNSS $(p=0.001)$, polyps size $(p=0.01)$, nasal congestion $(p=0.001)$,

No side effect

hinorrhea $(p=0.001)$, loss of smell $(p=0.001)$, headache $(p=0.001)$

(

IG: improvement of eotaxin, IL-5, IL-10 and TGFbeta $(\mathrm{p}<0.05)$ but no diffeand $n$ Treg cells improved

CG: no alteration of the level of any cytokines, eosinophil numbers and cells

4. Adherence
No side effect 


\begin{tabular}{|c|c|c|}
\hline Authors & Results & Side-effects \\
\hline Bonfils et al., 2015 & $\begin{array}{l}\text { 1. Bacteriology } \\
\text { Eradiaction of } 47 \% \text { of strains by } d 10 \text { in IG vs } 17 \% \text { in CG }(p=0.02) \\
\text { Less positive culture in IG ( } p=0.02) \\
\text { 2. Symptoms } \\
\text { No significant differences in symptoms between D0 vs D10 or D30 } \\
\text { 3. Compliance and adverse events } \\
\text { Excellent ( } 98.9 \% \text { in CG and } 97 \% \text { in IG) } \\
\text { Similar duration per application }\end{array}$ & $\begin{array}{l}5 \text { failures to take tobramycin } \\
27 \text { adverse events (none serious) (asthma } \\
\text { attack, cough, bronchitis, otalgia, otitis, } \\
\text { diarrhea, nausea and erythematous skin } \\
\text { lesions) } \\
\text { No difference between groups ( } \mathrm{p}=0.58 \text { ) }\end{array}$ \\
\hline Dai et al., 2017 & 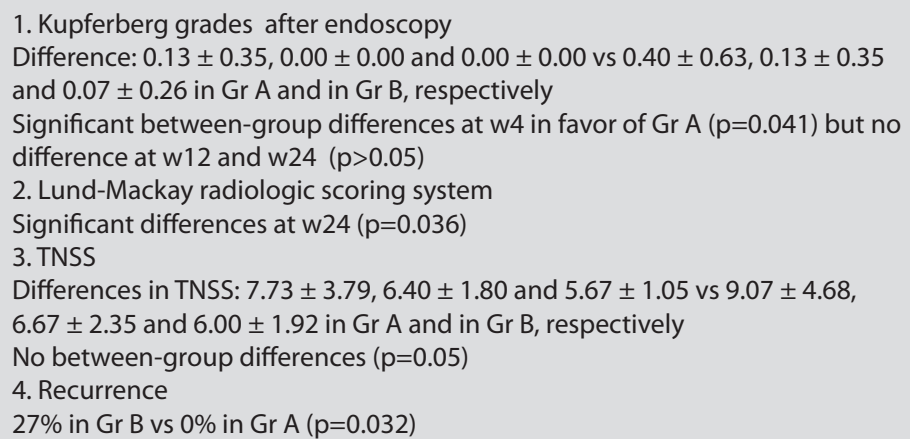 & NR \\
\hline
\end{tabular}

$\mathrm{CG}=$ control group / ND = non defined NA = non available / CRS = chronic rhinosinusitis / RSOM-31= Rhinosinusitis Outcome Measure/ RQLQ = Rhinoconjunctivitis Quality of Life / w = week/ $d=$ day $/ \mathrm{m}=$ month/ IL = interleukin/ SF-36 = The Short Form (36) Health Survey / VAS = visual analogue scale / IG = intervention group / CG = control group / AFRS = Allergic fungal rhinosinusitis/ OG = oral treatment $/ \mathrm{SPG}=$ spray nasal group / NebG $=$ nasal nebulization group.

interesting way to treat CRS, which is a common condition in the general population ${ }^{(3)}$. Globally, efficacy on symptoms, inflammation and quality of life was verified when nebulization was used as way of delivery.

Although the protocols and results related to nebulization are not homogeneous and vary depending on the nebulized drug and the comparator, based on the different studies included in this systematic review, we can conclude that nasal nebulization offers a valuable form of treatment in CRS. Our results justify the role of nebulization in the treatment of CRS as previously suggested by European guidelines ${ }^{(2)}$. Moreover, the dose of corticosteroids is lower when nebulized than the administered dose with oral delivery. However, the systemic absorption of corticosteroids when topically delivered by the nose has to be evaluated and taken into account ${ }^{(25)}$ even if the drug delivered by nasal route into the nose is quickly eliminated by mucociliary clearance or through the digestive tract ${ }^{(26)}$.

The efficacy of nebulized antibiotics or corticosteroids on symptoms was or tended to be significant in all studies. Indeed, symptoms decreased systematically after nebulized budesonide ${ }^{(14,15,20)}$. This improvement was similar to that of nasal spray delivery which remains the gold standard in CRS. It highlights that nebulization can be a potential alternative to nasal spray as a way of administering corticosteroids, even if it is more expensive and time-consuming. It is also an alternative to oral steroids without the risk of osteoporosis observed with this method of administration $^{(27)}$. Antibiotics administered by nasal nebulization were efficient ${ }^{(13,16,19)}$ although sometimes associated with side- effects $^{(13)}$. The efficiency of nebulized antibiotics has been considered as unconvincing in the past ${ }^{(28)}$. Nebulized saline alone was as efficient as nebulized tobramycin which confirms this view ${ }^{(16)}$. Nebulized antibiotics has therefore not been recommended in the guidelines until now. The presence of polyps seems to play an important role in the response to nebulization ${ }^{(21)}$. A recent systematic review on a similar topic also demonstrated that results depended on the presence of polyps ${ }^{(29)}$. We hypothesize that this could be explained by the impaction of the nebulized drug on the polyps. Nasal nebulization was demonstrated to de-

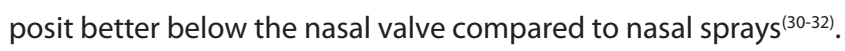
However, the improvement related to nebulization was not different compared to delivery by spray ${ }^{(15)}$.

Similar results were found regarding endoscopic parameters. Nebulized corticosteroids seem to be more efficient than all other treatments. Lund-Kennedy Endoscopic Score improved with nasal nebulization of antibiotics combined with other drugs $^{(18)}$. When patients were refractory to surgical and medical therapies, nebulized tobramycin offered a small benefit in terms of sinonasal endoscopy parameters ${ }^{(16)}$. This can be explained by the selected device showing inconsistent delivery into the sinu$\operatorname{ses}^{(33)}$. Nebulization of budesonide also demonstrated a small but significant improvement in Kupferberg grades compared to delivery of the same drug by nasal spray, with a reduction of edema ${ }^{(15)}$. In this study, the nebulizer was specific to sinus delivery ${ }^{(34)}$. PNIF improved without effect on nasal volume ${ }^{(14)}$. As this outcome was demonstrated to be an efficient tool to detect nasal patency changes ${ }^{(35,36)}$, it suggests improvement of nasal 
obstruction.

Surprisingly, quality of life was evaluated in only a few stu$\operatorname{dies}^{(14,16,19)}$. The benefits were not statistically significant but they were clinically relevant in the study using RQLQ, with an improvement greater than the minimal clinically important difference $(0.5 \mathrm{pts})^{(37)}$. As far as histological changes, endoscopy scores modification or nasal obstruction are concerned, the results are globally similar for all studies. Inflammatory markers were improved by nebulization of budesonide ${ }^{(20)}$.

This systematic review highlights a great disparity in the tools used in different studies. A similar observation was mentioned in a previous systematic review on the role of corticosteroids related to surgery ${ }^{(29)}$. Moreover, some non-specific scales were found in the studies, mainly to evaluate symptoms and nasal mucosa appearance. The nebulizers also differed between studies. We found a large number of specific nebulizers, few of which were delivering pulsatile aerosols. Sonic nebulizers were rarely used in the retrieved studies despite the fact that they improve sinusal deposition and delivery by the nasal route as suggested by different studies ${ }^{(34,38)}$. Moreover, the particle size of delivered aerosol varies between studies and could be not optimally adapted to sinus delivery.

Some limits need to be addressed regarding the results of this systematic review. First, that nebulization could be influenced by surgery, as one study demonstrated a significant lower total nasal deposition after surgery ${ }^{(30)}$. Inclusion criteria in the different studies varied on this point, although the majority of the studies did include patients with surgery. The delay between surgery and the experiments and the kind of surgery must also be taken into account. This is difficult because the delay varied from 6 weeks to 3 months and the surgical protocols were described poorly or not at all in the studies. Secondly, the inclusion of patients with polyps in some studies could also play a role in the results, as suggested previously in the discussion. Due to the heterogeneity of inclusion criteria related to the presence of polyps in the selected studies, a sub-analysis comparing CRS with and without polyps is not justified. Thirdly, the sample size is frequently too small to observe an effect. Fourthly, the control group received either saline nebulization or an administration of the same drug by nasal spray. The choice of saline as control in many studies can be questionable since nebulized saline so- lution improves outcomes in studies on chronic rhinosinusitis(39), as well as nasal volume similarly to inhaled steroids ${ }^{(14)}$. Similar benefit than with nasal spray can be considered positive since its efficacy as a method of treatment is largely supported in CRS with or without polyposis ${ }^{(5,40,41)}$. Nasal spray and saline solution were mentioned as a possible treatment in the European guidelines with a high level of evidence ${ }^{(2,39)}$. Other treatment modalities were not included in this review. Although nasal pressurized metered-dose inhalers dominate the market of devices for nasal drug delivery, other liquid formulations and nasal powder devices exist or are in development, and these have been the subject of previous research ${ }^{(42)}$. Mini-invasive options for delivery in the sinus have also been investigated elsewhere ${ }^{(43,44)}$.

\section{Conclusions}

In conclusion, this systematic review highlights that based on the present literature, nebulization is not better than nasal spray for the delivery of corticosteroids, with positive results observed in symptoms, endoscopic appearance and histological outcomes. For antibiotics, the results are less convincing and nebulization is not of added value for nasal delivery. Further large-scale studies are required to clarify the optimal protocol for treating CRS and to perform a cost-effectiveness analysis.

\section{Acknowledgements}

Gregory Reychler received a grant from the Institut de Recherche Expérimentale et Clinique (Université catholique de Louvain - Brussels - Belgium).

\section{Authorship contribution}

GR: guarantor of the paper, design and recording of the review, study selection, review and analysis, study details extraction and data interpretation, manuscript writing; CD: study selection, review and analysis, study details extraction and data interpretation, manuscript drafting; ACL: design of the review, data interpretation, manuscript drafting; FJ: design of the review, data interpretation, manuscript drafting; PR: design of the review, data interpretation, manuscript drafting

\section{Conflict of interest}

No conflict of interest.

\section{References}

1. Thomas M, Yawn BP, Price D, Lund V, Mullol J, Fokkens W. EPOS Primary Care Guidelines: European Position Paper on the Primary Care Diagnosis and Management of Rhinosinusitis and Nasal Polyps 2. Prim Care Respir J 2008;17(2):79-89.

2. Fokkens WJ, Lund VJ, Mullol J, et al European Position Paper on Rhinosinusitis and Nasal Polyps 2012. Rhinol Suppl 2012;(23):3-298
3. Lange B, Holst R, Thilsing T, Baelum J, Kjeldsen A. Quality of life and associated factors in persons with Chronic Rhinosinusitis in the general population. Clin Otolaryngol 2013;38(6):474-80.

4. Smith $T L$, Kern R, Palmer JN, et al. Medical therapy vs surgery for chronic rhinosinusitis: a prospective, multi-institutional study with 1-year follow-up. Int Forum Allergy Rhinol 2013;3(1):4-9.

5. Alobid I, Mullol J. Role of medical therapy in the management of nasal polyps. Curr Allergy Asthma Rep 2012;12(2):144-53.

6. Ah-See KL, MacKenzie J, Ah-See KW Management of chronic rhinosinusitis. BMJ 2012;345:e7054.

7. Petty DA, Blaiss MS. Intranasal corticosteroids topical characteristics: side effects, formulation, and volume. Am J Rhinol Allergy 2013;27(6):510-3.

8. Moller W, Schuschnig U, Meyer G, Mentzel $\mathrm{H}$, Keller M. Ventilation and drug delivery 
to the paranasal sinuses: studies in a nasa cast using pulsating airflow. Rhinology 2008;46(3):213-20.

9. Casale M, Sabatino L, Frari V, et al. The potential role of hyaluronan in minimizing symptoms and preventing exacerbations of chronic rhinosinusitis. Am J Rhinol Allergy 2014;28(4):345-8.

10. Moher D, Shamseer L, Clarke M, et al. Preferred reporting items for systematic review and meta-analysis protocols (PRISMA-P) 2015 statement. Syst Rev 2015;4:1.

11. Downs SH, Black N. The feasibility of creating a checklist for the assessment of the methodological quality both of randomised and non-randomised studies of health care interventions. J Epidemiol Community Health 1998;52(6):377-84

12. O'Connor SR, Tully MA, Ryan B, Bradley JM, Baxter GD, McDonough SM. Failure of a numerical quality assessment scale to identify potential risk of bias in a systematic review: a comparison study. BMC Res Notes 2015:8:224.

13. Bonfils P, Escabasse V, Coste A, et al. Efficacy of tobramycin aerosol in nasal polyposis. Eur Ann Otorhinolaryngol Head Neck Dis 2015;132(3):119-23.

14. Brown K, Lane J, Silva MP, DeTineo M, Naclerio RM, Baroody FM. A pilot study of the effects of intranasal budesonide delivered by NasoNeb(R) on patients with perennial allergic rhinitis. Int Forum Allergy Rhinol 2014:4(1):43-8.

15. Dai Q, Duan C, Liu Q, Yu H. Effect of nebulized budesonide on decreasing the recurrence of allergic fungal rhinosinusitis. Am J Otolaryngol 2017.

16. Desrosiers MY, Salas-Prato M. Treatment of chronic rhinosinusitis refractory to other treatments with topical antibiotic therapy delivered by means of a large-particle nebulizer: results of a controlled trial. Otolaryngol Head Neck Surg 2001;125(3):265-9.

17. Reychler G, Colbrant C, Huart C, et al. Effect of three-drug delivery modalities on olfactory function in chronic sinusitis. Laryngoscope 2015;125(3):549-55.

18. Shikani AH, Kourelis K, Alqudah MA, et al. Multimodality topical therapy for refractory chronic rhinosinusitis: our experience in thirteen patients with and twelve patients without nasal polyps. Clin Otolaryngol 2013:38(3):254-8.

19. Videler WJ, van Drunen CM, Reitsma JB, Fokkens WJ. Nebulized bacitracin/colimycin: a treatment option in recalcitrant chronic rhinosinusitis with Staphylococcus aureus? A double-blind, randomized, placebo-controlled, cross-over pilot study. Rhinology 2008;46(2):92-8

20. Wang $C$, Lou $H$, Wang $X$, et al. Effect of budesonide transnasal nebulization in patients with eosinophilic chronic rhinosinusitis with nasal polyps. J Allergy Clin Immunol 2015:135(4):922-9.
21. Shikani AH, Kourelis K, Rohayem Z, Basaraba RJ, Leid JG. Topical gel therapy for sinonasal polyposis in Samter's triad: preliminary report. Ann Otol Rhinol Laryngol 2012;121(11):719-24.

22. Bonfils P. [Nebulization aerosol therapy in otorhinolaryngology. Review of the literature]. Ann Otolaryngol Chir Cervicofac 1997;114(5):147-56

23. Macchi A, Terranova $P$, Digilio $E$ Castelnuovo P. Hyaluronan plus saline nasal washes in the treatment of rhino-sinusa symptoms in patients undergoing functional endoscopic sinus surgery for rhinosinusal remodeling. Int J Immunopatho Pharmacol 2013;26(1):137-45.

24. Wang C, Lou H, Lou W, Zhang L. [The efficacy and safety of a short course of budesonide inhalation suspension via transnasal nebulization in chronic rhinosinusitis with nasal polyps]. Lin Chung Er Bi Yan Hou Tou Jing Wai Ke Za Zhi 2012;26(8):347-50.

25. Lipworth BJ, Seckl JR. Measures for detecting systemic bioactivity with inhaled and intranasal corticosteroids. Thorax 1997;52(5):476-82.

26. Vecellio L, De Gersem R., Le Guellec S., et al. Deposition of aerosols delivered by nasal route with jet and mesh nebulizers. Int Pharm 2011;407(1-2):87-94

27. Winblad L, Larsen CG, Hakansson K Abrahamsen B, von BC. The risk of osteoporosis in oral steroid treatment for nasa polyposis: a systematic review. Rhinology 2017:55(3):195-201.

28. Goh YH, Goode RL. Current status of topical nasal antimicrobial agents. Laryngoscope 2000;110(6):875-80

29. Pundir V, Pundir J, Lancaster G, et al. Role of corticosteroids in Functional Endoscopic Sinus Surgery--a systematic review and meta-analysis. Rhinology 2016;54(1):3-19.

30. Moller W, Schuschnig U, Celik G, et al. Topical drug delivery in chronic rhinosinusitis patients before and after sinus surgery using pulsating aerosols. PLoS One 2013;8(9):e74991.

31. Suman JD, Laube BL, Dalby R. Comparison of nasal deposition and clearance of aerosol generated by nebulizer and an aqueous spray pump. Pharm Res 1999;16(10):1648 52.

32. Miller TR, Muntz HR, Gilbert ME, Orlandi RR. Comparison of topical medication delivery systems after sinus surgery. Laryngoscope 2004:114(2):201-4.

33. Negley JE, Krause H, Pawar S, Reeves-Hoche MK. RinoFlow nasal wash and sinus system as a mechanism to deliver medications to the paranasal sinuses: results of a radiolabeled pilot study. Ear Nose Throat $J$ 1999;78(8):550-4

34. Moller W, Schuschnig U, Khadem SG, et al Pulsating aerosols for drug delivery to the sinuses in healthy volunteers. Otolaryngol Head Neck Surg 2010;142(3):382-8.

35. Teixeira RU, Zappelini CE, Alves FS, da Costa EA. Peak nasal inspiratory flow evalua- tion as an objective method of measuring nasal airflow. Braz J Otorhinolaryngol 2011;77(4):473-80

36. Wilson AM, Sims EJ, Robb F, Cockburn W, Lipworth BJ. Peak inspiratory flow rate is more sensitive than acoustic rhinometry or rhinomanometry in detecting corticosteroid response with nasal histamine challenge. Rhinology 2003;41(1):16-20.

37. Juniper EF, Guyatt GH, Griffith LE, Ferrie PJ. Interpretation of rhinoconjunctivitis quality of life questionnaire data. J Allergy Clin Immunol 1996;98(4):843-5.

38. Durand M, Le Guellec S., Pourchez J, et al. Sonic aerosol therapy to target maxillary sinuses. Eur Ann Otorhinolaryngol Head Neck Dis 2012;129(5):244-50.

39. Majima Y, Sakakura Y, Matsubara T, Murai S, Miyoshi Y. Mucociliary clearance in chronic sinusitis: related human nasal clearance and in vitro bullfrog palate clearance. Biorheology 1983;20(2):251-62.

40. Kemp JP, Berkowitz RB, Miller SD, Murray JJ, Nolop K, Harrison JE. Mometasone furoate administered once daily is as effective as twice-daily administration for treatment of mild-to-moderate persistent asthma. J Allergy Clin Immunol 2000;106(3):485-92.

41. Penagos M, Compalati E, Tarantini F, BaenaCagnani CE, Passalacqua G, Canonica GW. Efficacy of mometasone furoate nasa spray in the treatment of allergic rhinitis. Meta-analysis of randomized, double-blind, placebo-controlled, clinical trials. Allergy 2008:63(10):1280-91.

42. Djupesland PG. Nasal drug delivery devices: characteristics and performance in a clinical perspective-a review. Drug Deliv Transl Res 2013;3(1):42-62.

43. Rizan C, Elhassan HA. Post-sinus surgery insertion of steroid-eluting bioabsorbable intranasal devices: A systematic review. Laryngoscope 2016;126(1):86-92.

44. Taulu R, Bizaki AJ, Numminen J, Rautiainen M. A prospective, randomized clinical study comparing drug eluting stent therapy and intranasal corticoid steroid therapy in the treatment of patients with chronic rhinosinusitis. Rhinology 2017;55(3):218-26.

\author{
Gregory Reychler \\ Pneumology Unit \\ Cliniques Universitaires St-Luc (UCL) \\ Avenue Hippocrate 10 \\ 1200 Brussels \\ Belgium
}

E-mail:

gregory.reychler@uclouvain.be 